\title{
The Development of Learning Model Based on Research and Relevance Journal for Postgraduate Students' Scientific Publications of Economic Postgraduate Program
}

\author{
Yulhendri ${ }^{1}$, Efrizal Syofyan ${ }^{2}$, Silsiya Afridona ${ }^{3}$ \\ ${ }^{1}$ Lecturer, Padang and Indonesia, $\square$ (e-mail) yulhendriunp@gmail.com \\ ${ }^{2}$ Lecturer, Padang and Indonesia, $\square$ (e-mail) efrizal_syofyan@yahoo.com \\ 3Post Graduates, Padang and Indonesia, $\bowtie$ (e-mail) silsiyaafridona@gmail.com
}

\begin{abstract}
This article describes the students' low reasoning ability of the Economics Master Program in writing scientific journals and thesis that are still based on the old theory and common sense, so it is necessary to apply an attractive learning model that is research based learning with inquiry approach. This research uses development research design (Research and Development, R \& D). The result of the research shows that there is an increase of students intellectual skill in reasoning and narrating the references based on the international journal that cited in writing journal and students' thesis, but not yet significant. For that purpose, it needed a follow-up of this development research in the following year.
\end{abstract}

Keywords: research based learning, intellectual skill, scientific journal

\section{Introduction}

This research is motivated by the low ability of students in analyzing the real problems found related to the lecture material in the subject of The Economic Learning Strategy and The Advanced Macro Economics Theory of students in the Economics Postgraduate Program by connecting it with previous research on the international scale. Students have difficulties in interpreting the problems found with relevant research, that can be seen in students' low ability to write scientific papers.

Accordingly, new findings in science can be traced through scientific papers. Scientific papers result from solving a problem based on investigation, observation, data collection obtained from a research, either field research, laboratory tests, or literature review based on logical and empirical thinking and scientific methods.

But in fact it is difficult to motivate students to write a scientific paper, such as in writing a journal. For instance, not many students understand how to write good journals, especially international journals. Another factor is the students' knowledge of the theories used in research is very limited, still based on the old theory, and the context used is still based on common sense. For that it takes a hard effort to form a student mindset that writing scientific papers is one achievement of improving the graduate's quality of a college.

Based on the researcher's observation, there is an inconsistency between the perspectives that the higher education institution creates graduate who are able to think high-level with the reality found in the students of Economic Education Postgraduate Program of Universitas Negeri Padang. Students of postgraduates with higher education level than Strata One should have better intellectual and logical skills. This is seen when students are asked to write a scientific journal, utilizing the reference of accredited international research, students have difficulty in connecting the topic of problems found with relevant research. Students' difficulties were in comprehending the gap theories contained in international journals are used as a reference, there are even students have difficulty in comprehending the content of the journal. This happens because there are not many lecturers who 
direct students to cite these accredited journals in writing the scientific articles. And it also seen in thesis writing by students, they are accustomed to copy the old theory that already existed on the previous student thesis collection that has graduated. So that it formed a mindset that writing thesis and scientific article only as one of fulfillment requirement to reach Magister degree. But they do not understand the essence of their writing, which a scientific article or a thesis made by students to should be a reference from the educator to evaluate the extent to which the development of science and the ability of students and its implementation in the institutions of higher education where the lecturer teach. So if it mapped in a road map of college research, the development of research, technology, and knowledge in an institution of higher education will run in place. The following figures describe the h-index journal in Asia based on Scimago data.

Table1 H-index and Country Rank in Asia period of year 1996-2015

\begin{tabular}{ccccc}
\hline Rank & Country & Documents & $\begin{array}{c}\text { Citations per } \\
\text { document }\end{array}$ & H index \\
\hline 1 & China & 4076414 & 5.93 & 563 \\
2 & Japan & 2212636 & 13.76 & 797 \\
3 & India & 1140717 & 7.41 & 426 \\
4 & South Korea & 824839 & 10.28 & 476 \\
5 & Taiwan & 532534 & 10.56 & 363 \\
6 & Hong Kong & 219177 & 15.94 & 392 \\
$\mathbf{7}$ & Singapore & $\mathbf{2 1 5 5 5 3}$ & $\mathbf{1 4 . 5 5}$ & $\mathbf{3 9 2}$ \\
$\mathbf{8}$ & Malaysia & $\mathbf{1 8 1 2 5 1}$ & $\mathbf{4 . 9}$ & $\mathbf{1 9 0}$ \\
$\mathbf{9}$ & Thailand & $\mathbf{1 2 3 4 1 0}$ & $\mathbf{9 . 5 8}$ & $\mathbf{2 3 6}$ \\
10 & Pakistan & 94285 & 5.79 & 166 \\
$\mathbf{1 1}$ & Indonesia & $\mathbf{3 9 7 1 9}$ & $\mathbf{7 . 1 2}$ & $\mathbf{1 5 5}$ \\
12 & Bangladesh & 30612 & 7.43 & 134 \\
13 & Viet Nam & 29238 & 8.68 & 142 \\
$\mathbf{1 4}$ & Philippines & $\mathbf{2 0 3 2 6}$ & $\mathbf{1 3 . 0 7}$ & $\mathbf{1 6 3}$ \\
15 & Sri Lanka & 12557 & 9.69 & 120 \\
\hline Source: http://scimagojr.com & & &
\end{tabular}

The table above explains that Indonesia ranked 11th for the number of successful publication in international scientific journals with a total of 39,719 journals, with the number of citations per journal document of 7.12, and the h-index number of 155 at the level of Asian countries. This figure is lower than the closest country Indonesia such as Malaysia. The country has published 181,251 journals, with the h-index of 190. Indonesia lags far enough from Malaysia for the number of scientific journals published through international publications. This indicates that Indonesia still needs to improve the curriculum or learning method for universities. Learning methods used should be methods that train students' reasoning abilities and make students accustomed to reading accredited international journals, as well as familiarize students writing scientific papers.

Universitas Negeri Padang as one of the central research institutions, when viewed on the h-index still in rank 65 (data of Sinta Ristekdikti, 2016). Universitas Negeri Padang has not been successfully entered into 50 Scopus Indexed Higher Education Institutions in Indonesia. This is due to the level of students' skills in writing scientific journals need to be further improved. Another factor is the lecturer delay in starting to familiarize students using international journals as a reference in writing thesis. 
The above explanation illustrates that in an effort to improve academic ability, it is needed a learning strategy that is able to explore the level of students rationality, that is a research-based learning model. They are required to be able to distribute an economic or social/political problem in the reality of their life, then analyze problem and alternative solution to the problem. It is assumed that research-based learning can improve intellectual skill level of students (Nuchwana, 2012).

One of the important indicators to be considered in research-based learning is the involvement of research elements in the learning process. This is because the research-based learning (RBL) is authentic with the perspective of problem formulation, alternative solutions, and how the implementation of the research results provide benefits in shaping the way and level of student thinking.

Research-based learning is a multifaceted concept that illustrates the new faces of learning strategies that connect research and teaching. Good research-based learning practices should involve 4 aspects: 1) research results should have an impact on the curriculum, 2) teaching and learning methods should be research-based, 3) learning must use the elements of research,4) RBL should be able to develop a context inclusive research(Srikoon, 2014). Consequently, according to a study in Ukraine, it can be concluded that research-based learning has complex pedagogical goals, coupled with the fundamental task of developing student research competencies (developing skills to design a research task and finding ways to overcome it) (Pavliuk, Liakh, Bezpalko, \&Klishevych, 2017).

Research-based learning can improve academic achievement, increase the level of educational goals to the level of how to learn and build new knowledge that benefits both yourself and the environment (Blackmore \& Fraser, 2007). These competencies are very important for education in the 21st century (Brew \& Brew, 2010).

The rapid development of science and technology takes place in various place of the world, with respect to that research-based learning is an appropriate learning model used in higher education institutions. Because RBL is not only able to increase students' knowledge, but also cognitive ability, thinking ability, creative thinking and learning (Sota\&Peltzer, 2017). Students are directed to active learning, and continuously search for the latest research results and analyze then synthesis and implementation to discover new knowledge. Some previous research has proved that research-based learning is more effectively compared to conventional learning methods (Ambrose, 1996).

Basically, research-based learning aims to create a learning process that leads to the activities of analysis, synthesis, and evaluation and improve the ability of students and lecturers in terms of assimilation and application of knowledge. The purpose (Widyawati, Tri Diah, 2010) can be described as follows: 1) Increasing the meaning of the course to be more contextual through the exposure of research results2) Strengthening students' thinking skills as researchers3) Complete the learning through internalization of research, practice, and research ethics value by involving research4) Improving the quality of research in universities and involving students in research activities5) Improving students' understanding of the science development through continuous research6) Improve the understanding of research role in innovation so as to encourage students to always think creatively in the future7) Improve the quality of learning in general.

This research aims to improve the student's ability to write scientific papers, where in the implementation students trained with a high-order thinking. Increasing the ability to write scientific papers means an increased in the ability of students' intellectual skills. In addition, this research aims to change the direction of research that is still based on the old theory into new theory-based research. The output of this research is a scientific journal which is worthy of publication from student's work. 


\section{Methods}

In the Method section, you explain clearly how you conducted your study in order to: (1) enable readers to evaluate the work performed and (2) permit others to replicate your study. You must describe exactly what you did: what and how experiments were run, what, how much, how often, where, when, and why equipment and materials were used. The main consideration is to ensure that enough detail is provided to verify your findings and to enable the replication of the study. You should maintain a balance between brevity (you cannot describe every technical issue) and completeness (you need to give adequate detail so that readers know what happened).

In the first year of this research use development research design (Research and Development, R \& D) (Research and Development, R \& D). Development Research is a collection, processing, analysis, and presentation of data that is done systematically and objectively accompanied by activities to develop a product to solve a problem faced. Sugiyono (2012: 407) states that development research is a research method used to produce a particular product and test the effectiveness of the product.

The research was conducted on the Master Program of Economic Education Universitas Negeri Padang with a sample of students class X and XI in three courses, namely: The Advanced of Macroeconomic Theory, The Advanced of Economic Learning Strategy, and International Accounting. This study was conducted with several procedures. Such procedures include the planning, exploration, early product development, validation and final revisions. The first stage is the planning that includes the preparation of research steps, development of Research-Based tools for the subjects of Economic Learning Strategies, and Advanced Macro Economics Theory and International Accounting. The second stage is exploration. The exploration stage involves the process of documenting the research results in accordance with the subject area of the study on the syllabus.

The third stage is initial product development, in the form of a revision of the syllabus (if required), the making of the Course Events Unit (SAP), learning video material, task design, case, exercises and issues to be discussed in the classroom and the learning model to be applied. The preparation of this learning tool will be done by involving lecturer team of subjects, lecturer of economic learning strategy and optimizing e-learning which have been available at e_learning.unp.ac.id.

The first validation activity is a theoretical validation pursued through an expert examination or a panelist who assesses the research results selected on articles downloaded from international journals which are reputed in the last 10 years, the learning tools that have been prepared. This step is done by using Focus Group Discussion (FGD) with lecturer of the subject's, lecturer of learning strategy and also team of IT experts as described previously. It will also involve some students to see the students' initial responses to articles from journals that have been downloaded.

Furthermore, for the second year of this research will develop into a design research. Design research is considered a research paradigm that aims to develop a sequence of activities and understand an empirical understanding of how learning works (Mckenney, 2004) (Cobb et al., 2001; Edelson, 2002; (Mckenney, 2004); Research Advisory Committee, 1996; Widjaja, 2008). Furthermore, Wang \& Hannafin (in Wijaya 2008) also defines design research as a systematic but flexible method, aimed at improving teaching practice through repetitive analysis, repetitive design, and implementation, refers to collaborations between researchers and practitioners with daily life situations, and leads to contextual sensitive design principles and theories. 


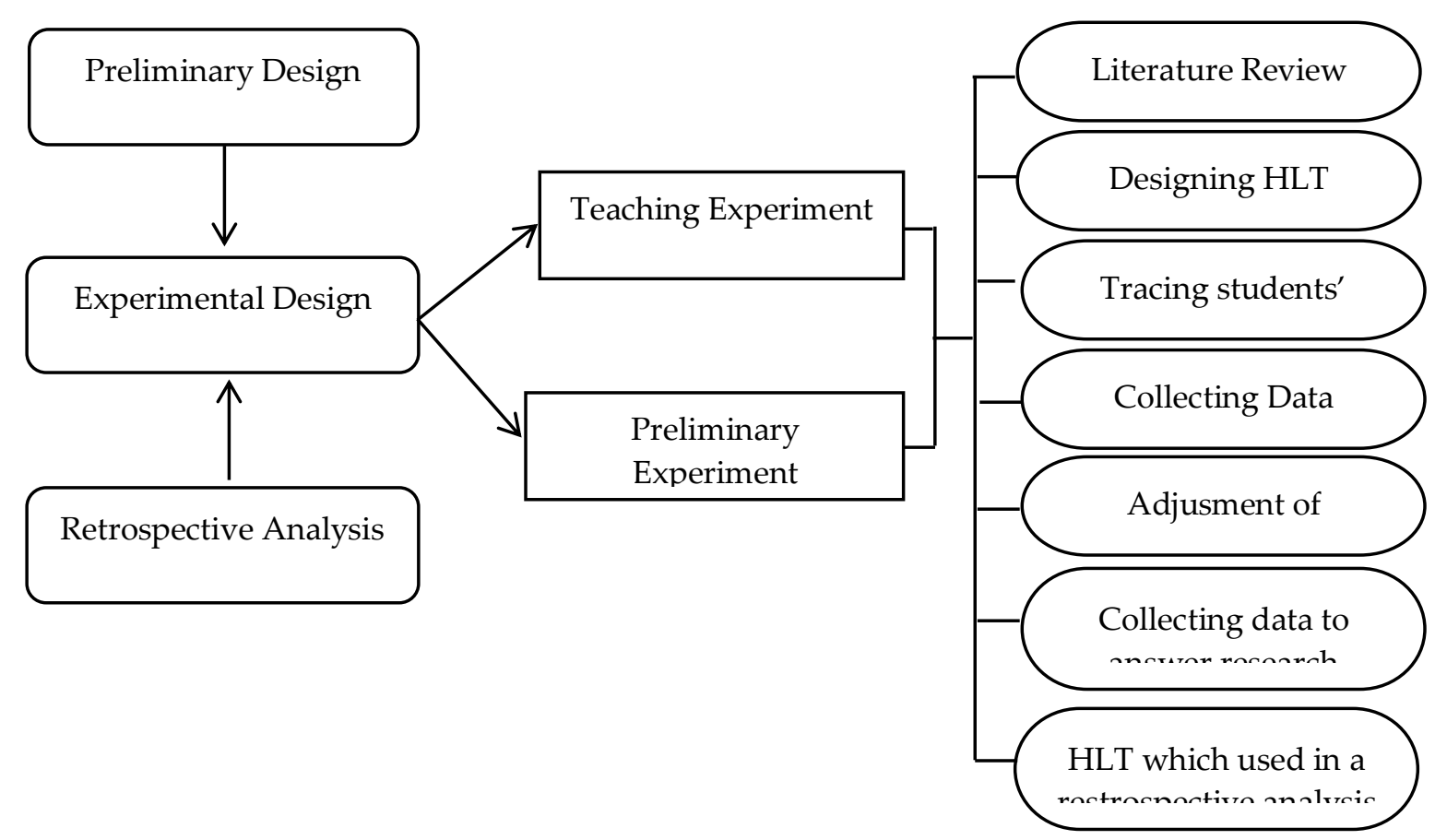

Gravemeijer Design Design Research Scheme

\section{Results and Discussion}

Early ability test results before being given research based learning in experimental class, it is known that the level of respondents achievement of $38.3 \%$ in the category of less good. This is indicated by the initial ability possessed by the respondent based solely on experience alone. In addition, the low ability of writing respondents due to less accustomed to writing scientific papers. Therefore, follow-up by giving the task of writing scientific papers. This activity is done to motivate students to be more active writing. And the results show that there is an increase in student writing skills. The average writing ability of students increased by $30.3 \%$, so the ability to write current students to $68.6 \%$ in the category is quite good. This result can be seen from the task of scientific work done by the students. So it can be concluded that for the initial knowledge test results, there are differences but not significant enough between the experimental class and control class before treatment is given.

The results of the respondents' achievement level for the ability to concoct a sentence until it becomes a paragraph obtained a value of $24 \%$ in the low or not good category. The low ability of students in concocting a sentence into a paragraph is influenced by various factors. Therefore, it is needed a follow-up to overcome this problem by providing information on how to write well. Information on writing procedures is given in great detail to develop students' ability to explore their thinking so that they can create a series of good and relevant paragraphs. From the results of followup activities, an increase in the ability of students to $46.5 \%$. It can be said that the improvement of ability is $22.5 \%$ which characterized by the ability of the words preparation in the study of theory on students' scientific writing.

The results of the test on the overall achievement level of students revealed that students' critical thinking and writing skills are in good enough category with a result of $50.7 \%$. Because the student's ability in general is good enough, the follow-up activities undertaken to maintain and improve the ability of students becomes better. Follow-up activities are carried out by giving a phenomenon and a 
problem about the current macro economy that should be analyzed and developed by respondents. The results obtained there is an increase in students' critical thinking and writing skills. amounting to $67.6 \%$.

This research is in line with the research conducted by Roach, Blackmore, Dempster (2000), the said an educational development project has been designed to encourage staff in research-led universities to use learning technologies in their teaching. The possible links between research and teaching are explored and the centrality of learning is noted. A distinction is made between 'adoptive' and 'adaptive' learning and the relationship of these terms to 'deep' and 'surface' learning considered. Some principles for a research-based educational framework are proposed and the importance of emphasized. Uses of learning technologies that support adoptive and adaptive learning are outlined and issues for further study are identified. Their research revealed that educational developers in research-led universities therefore face particular challenges. It certainly helps us if we appear to be living in the same world as the academic staff that we seek to assist. This is not simply a political strategy. We hope we have shown that many of the enduring concerns of educators internationally and across all disciplines and phases of education can profitably be tackled in research-intensive institutions through a closer concentration on research-led teaching. We believe that in stressing the centrality of research processes as a model for undergraduates' learning processes we are working with the grain of research-led institutions and helping to articulate an approach to teaching that resonates with academics' own values and beliefs and is attractive to them (Roach, Blackmore, \&Dempster, 2000).

Based on this research, obtained that the Postgraduate Program students of 2016 academic year in Economic Faculty who has graduated by 3 semesters is only about 33\%, because they have finished their thesis research well, while $10 \%$ has finished by 4 semesters. And $57 \%$ of students are still in finishing the thesis research process, because they are constrained in writing the thesis. It indicates that it is needed a learning model in fostering the students to write the thesis and journal, that is Research Based Learning Model.

Another relevance research was conducted by Srikoon, et al, (2013), their research showed that research-based learning (RBL) is a part of learning process in order to construct the essential skills in 21st century. Currently, there are not many studies about the body of knowledge on research-based learning in Thailand. So, the objective of this research is to synthesize the research-based learning. Variables consist of two sets. First set is the description of research. Second set is the effect sizes of research. Tool for collecting data is the recording data form for research synthesis. Data were analyzed by frequency, percentage and meta-analysis. The results showed that (1) description of research, we found that in 2009, RBL research was frequently published (26.1\%), Chulalongkorn University often produced RBL research $(26.1 \%)$, there were two majors which usually produced the RBL research as Research, Measurement and Evaluation major (21.7\%) and Science Education major (21.7\%), researchers from the Office of the Higher Education Commission commonly produced the research $(39.1 \%)$, most were male researchers $(82.6 \%)$, the research type was thesis in master degree (69.6\%), common research objectives found was to study $(46.5 \%)$, research design most found was experimental design $(82.6 \%)$, frequent sample found was students $(31.3 \%)$, samples' research level was secondary school (43.5\%) and repeated analyzing method found was descriptive analysis (48.65\%). (2) the effect sizes from RBL influence independent variables comprising of the knowledge discovery and working skills, good citizen, thinking skills, achievement, nature researcher, basic research, problem solving skills, critical thinking, inquiry and attitude (Srikoon, 2014).

It can be concluded that research-based learning can improve students' writing skills in scientific journals, through reading international journals of previous research, linking them to real issues seen by students, then writing them in a journal. The student has been able to narrate the journal read and his thoughts then write with the syllogism of good thinking and critical thinking. In addition, research-based learning is also able to improve students' intellectual and English skills. 


\section{Conclusions}

Research-based learning is a form of learning model which in its implementation process uses scientific journals, research results and relevant research related to lecturing material. In general, the steps in research-based learning consist of the preparatory phase, the methodology application stage and the research stage and the publication.

The findings of the research indicate that there is an increase in the students 'ability to write scientific journals, but this increase has not been significant enough because the percentage of students who are able to write the journal is smaller than the number of samples, and the students' writing results cannot be categorized as worthy of publication in international journals. Related to these problems according to the researcher can be improved to become a journal worthy of publication through the application and habituation of research-based learning.

The improvement of students' ability is evident from the ability to find relevant references, the proper use of language, the ability to refer sources that lead to reputable journals, the ability of students to understand theories, analyze the material, and the ability to read research models, all of which are indicators of writing ability students who have sufficiently met the criteria of scientific journals that deserve publication despite the national scale. Furthermore, for the ability to combine research/concocting relevant research into a series of paragraphs have not met either category. For students' critical thinking and writing skills also increased.

Implementation of research-based learning on the Postgraduate Program of Economics Education Universitas Negeri Padang is the right model used for improving the ability to write scientific journals and intellectual skills of students. Students are getting used to making international journals as a reference in writing scientific papers such as theses and journals, and the habit of copying theories from the theses in the library is diminishing. This condition is a positive change in spurring h-index numbers of Universitas Negeri Padang.

It is expected that the lecturers will be able to apply and develop this research-based learning model in a sustainable manner. So that the State University of Padang, especially the Master Program of Economic Education is able to produce quality scientific journals and decent national and international publications are indexed and reputable.

\section{References}

Ambrose, S. (1996). Session 1213 Changing the Culture: What at the center of engineering education, $1-7$.

Brew, A., \& Brew, A. (2010). Higher education research \& development imperatives and challenges in integrating teaching and research imperatives and challenges in integrating teaching and research, (June 2013), 37-41. https://doi.org/10.1080/07294360903552451

Mckenney, S. (2004).Educational Design Research.

Nuchwana, L. (2012). How to link teaching and research to enhancestudents' learning outcomes. International Conference on Education and Educational Psychology (ICEEPSY 2012): Thai University Experience. Procedia-Socialand Behavioral Sciences, 69(Iceepsy),213-219. https://doi.org/10.1016/j.sbspro.2012.11.401

Pavliuk, R. O., Liakh, T. L., Bezpalko, O. V, \& Klishevych, N. A. (2017). Research-based training : methodological characteristics and results of the analysis of educational programs, (September), 1-13. https://doi.org/10.20944/preprints201709.0128.v1

Roach, B. M., Blackmore, P., \&Dempster, J. (2000).Supporting high level learning through researchbased methods and e-learning Guidelines for course design methods : Interim guidelines for course design.

Sota, C., \&Peltzer, K. (2017). The efffectiveness of research based learning among master degree student for health promotion and preventable disease Faculty of Public Health ,Khon Kaen University , Thailand. Procedia - Social and Behavioral Sciences, 237(June 2016), 1359-1365. 
https://doi.org/10.1016/j.sbspro.2017.02.226

Srikoon, S. (2014). Research synthesis of research-based learning for education in Thailand, 116, 913917. https://doi.org/10.1016/j.sbspro.2014.01.319

Widyawati, Tri Diah, U. G. M. (2010). Pedoman Umum Pembelajaran Berbasis Riset (PUPBR). Universitas Gajah Mada, 15. 